\title{
Turkish Nationwide SurvEy of Glycemic and Other Metabolic Parameters of Patients with Diabetes Melitus (TEMD Study)
}

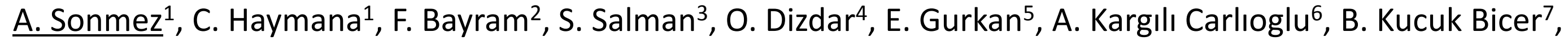
C. Barcin ${ }^{8}$, T. Sabuncu ${ }^{9}$, I. Satman ${ }^{10}$, TEMD Study Group $^{11}$

${ }^{1}$ Gulhane School of Medicine and Gulhane Training and Research Hospital, Department of Endocrinology and Metabolism, ${ }^{2}$ Erciyes University School of Medicine, Department of Endocrinology and Metabolism, ${ }^{3}$ Liv Hospital, Department of Endocrinology and Metabolism, ${ }^{4}$ Kayseri Training and Research Hospital, Department of Endocrinology and Metabolism, ${ }^{5}$ Hatay State Hospital, Department of Endocrinology and Metabolism, ${ }^{6}$ Erzurum Training and Research Hospital, Department of Endocrinology and Metabolism, ${ }^{7}$ Yuksek Ihtisas University School of Medicine, Department of Public Health, ${ }^{8}$ Gulhane School of Medicine, Department of Cardiology, ${ }^{9}$ Harran University School of Medicine, Department of Endocrinology and Metabolism, ${ }^{10}$ Istanbul University School of Medicine, Department of Endocrinology and Metabolism, ${ }^{11}$ The members of the Society of Endocrinology and Metabolism of Turkey from 68 Tertiary Endocrine Units

\section{Background :}

Blood glucose is not the only predictor of cardiovascular outcome in diabetes. Optimization of other metabolic parameters such as lipids, arterial blood pressure (ABP), and body weight as well as a healthy lifestyle are utmost important.

Aim:

The primary aim of this nationwide survey was to find out the achievement of glycemic and other metabolic control parameters in Turkish adult patients with type 1 or type 2 diabetes. The secondary aim was to find out the best predictors of optimal metabolic control.

\section{Methods:}

Patients who were under follow-up in the same center for at least a year were registered sequentially between 01 April and 30 June 2017, in 68 tertiary endocrine units, in 37 cities. Demographic, anthropometric, clinical and biochemical data, including medications were recorded for each patient. Blood Pressures were measured by standardized electronic sphygmomanometers. Both current and former (previous 12 to 18 moths) laboratory data were recorded.

Exclusion Criteria: Pregnancy, Age <18years, Decompensated liver disease, Psychiatric disorders interfering cognition or compliance, Bariatric surgery, Renal replacement therapy.

Statistical analysis: Logistic regression was performed to analyze the independent determinants of current $\mathrm{HbA1c}$ levels.

Results

A total of 5240 patients with type 1(9.1\%) and type 2 diabetes(90.9\%) were enrolled (Table-1). Patients with type 1 diabetes had worse glycemic control than type $2(8.69 \pm 1.97 \%$ vs. $7.73 \pm 1.75 \%$; $p<0.001)$. Figure-1 depicts the percentage of patients with controlled metabolic parameters and living a healthy lifestyle (HbA1c $\leq 7.0 \%$, LDLcholesterol(LDL-C) $<100 \mathrm{mg} / \mathrm{dl}$, Arterial Blood Pressures (ABP) $<140 / 90$ $\mathrm{mmHg}$, Body Mass Index (BMI) between $18.5-30 \mathrm{~kg} / \mathrm{m}^{2}$, Non-smoker and performing regularly exercise (>60 min/week)).

Patients who met the HbA1c, LDL-C and ABP goals:

Type 1 diabetics $\quad \mathrm{n}=28(6.0 \%)$

Type 2 diabetics $\quad n=446(9.6 \%)$

Patients who met the additional healthy lifestyle goals:

Type 1 diabetics $\quad \mathrm{n}=17(3.6 \%)$

Type 2 diabetics $\quad n=190(2.7 \%)$

The alteration of HbA1c levels in the follow up

$\begin{array}{llll} & \text { Previous } & \text { Current } & \\ \text { Type } 1 \text { diabetics } & 8.84 \pm 2.09 \% & 8.69 \pm 1.98 \% & \mathrm{p}=0.079 \\ \text { Type 2 diabetics } & 7.90 \pm 1.88 \% & 7.71 \pm 1.73 \% & \mathrm{p}<0.001\end{array}$

The significant determinants of optimal HbA1c in patients with type 2 diabetes are given in Table-2. In type 1 diabetes, only the higher income Odds Ratio 3.039 (95\% Cl:1.082-8.538) is the significant determinant of optimal HbA1c.

Figure-1: The percentage of patients with optimal glycemic and metabolic control.

-Type 1 Diabetes
-Type 2 Diabetes

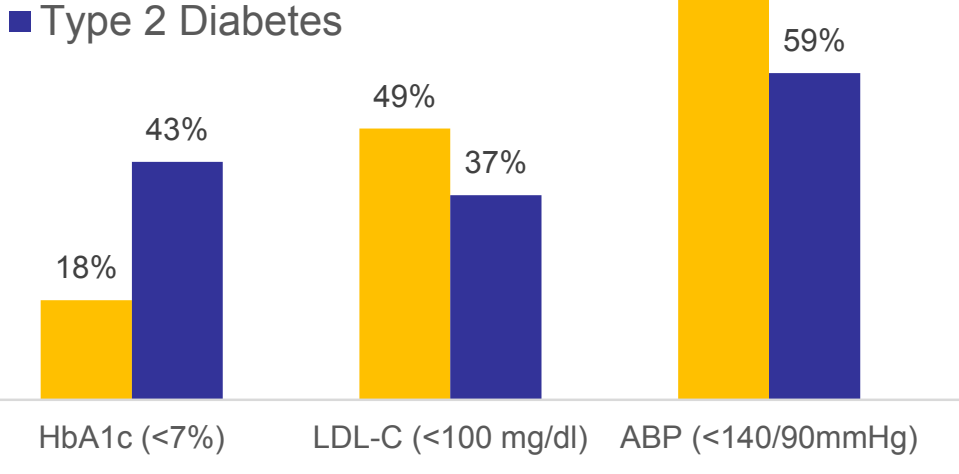

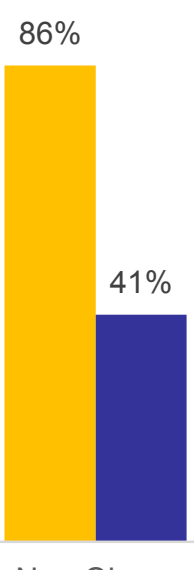

Table-1: Demographic and laboratory parameters of patients with type 1 and type 2 diabetes in Turkey

\begin{tabular}{|c|c|c|}
\hline & $\begin{array}{l}\text { Type } 1 \text { diabetes } \\
\quad(n=476)\end{array}$ & $\begin{array}{c}\text { Type } 2 \text { diabetes } \\
\qquad(n=4764)\end{array}$ \\
\hline Number & 476 (9.1\%) & 4764 (90.9\%) \\
\hline Female & 288 (61.0\%) & 2792 (58.9\%) \\
\hline Age, year & $34.4 \pm 12.9$ & $58.4 \pm 10.6$ \\
\hline Waist Circumference, $\mathrm{cm}$ & $85.1 \pm 11.9$ & $104.5 \pm 14.1$ \\
\hline $\mathrm{BMI}, \mathrm{kg} / \mathrm{m}^{2}$ & $23.8 \pm 4.6$ & $31.7 \pm 7.4$ \\
\hline SBP (Office), mmHg & $118.2 \pm 15.4$ & $132.5 \pm 18.3$ \\
\hline DBP (Office), mmHg & $74.4 \pm 9.5$ & $80.5 \pm 10.8$ \\
\hline SBP (Home), mmHg & $113.4 \pm 12.8$ & $125.8 \pm 13.6$ \\
\hline DBP (Home), mmHg & $72.1 \pm 9.3$ & $77.6 \pm 8.8$ \\
\hline HbA1c, \% & $8.69 \pm 1.97$ & $7.73 \pm 1.75$ \\
\hline Diabetes duration, year & $13.5 \pm 10.2$ & $10.9 \pm 7.6$ \\
\hline LDL-C, mg/dl & $106.9 \pm 36.9$ & $113.9 \pm 36.1$ \\
\hline HDL-C, mg/dl & $57.4 \pm 17.6$ & $46.8 \pm 16.2$ \\
\hline Triglycerides, $\mathrm{mg} / \mathrm{dl}$ & $114.0 \pm 148.9$ & $182.9 \pm 131.1$ \\
\hline
\end{tabular}

Table-2: The determinants of HbA1c levels in Type 2 diabetics

\begin{tabular}{|l|l|}
\hline & Odds Ratio (95\% Cl) \\
\hline $\begin{array}{l}\text { Center (governmental vs private) } \\
\text { Duration of diabetes } \\
>\mathbf{1 1} \text { years ref }\end{array}$ & $1.792(1.179-2.723)$ \\
\hline \multicolumn{1}{|c|}{$\mathbf{6 - 1 0}$ years } & \\
\hline \multicolumn{1}{|c|}{$\mathbf{4 0 - 6 4}$ years } & $0.317(0.254-0.394)$ \\
\hline Age 18-40 ref & $0.538(0.436-0.665)$ \\
\hline \multicolumn{1}{|c|}{ Middle income } & $1.309(1.071-1.599)$ \\
\hline Waist circumference & $2.700(1.702-4.282)$ \\
\hline Smoking income & $0.712(0.592-0.841)$ \\
\hline Self Monitoring Blood pressure & $0.657(0.597-0.850)$ \\
\hline Income High income ref & NS \\
\hline & $1.371(1.051-1.788)$ \\
\hline & $1.581(1.180-2.118)$ \\
\hline LDL- C & NS \\
\hline HDL-C & $1.251(1.045-1.496)$ \\
\hline TG & $0.731(0.611-0.873)$ \\
\hline DM education & $0.776(0.640-0.940)$ \\
\hline Microvascular complications & $0.734(0.598-0.902)$ \\
\hline
\end{tabular}

\section{Discussion}

The results of the TEMD study show that very few diabetic patients living in different regions of Turkey have optimal metabolic control, despite the fact that all the enrolled patients were under follow-up in tertiary endocrine and diabetes units. In order to make a progress in the diabetes health care, better follow-up policies should be implemented to overcome the negative determinants of optimal metabolic control. 